\title{
Anomalía de Peters o disgenesia mesodérmica de la córnea
}

I)res.: M. Aspillaga H.". V. Mosca R.**. I. Avendaño B.", G. Morizon 1. ."

Desde principios de este siglo llamó la atención a los oftalmólogos una afección que comprometía la córnea desde el nacimiento, produciendo leucoma y pudiendo asociarse a otras alteraciones oculares. ${ }^{1}$ Posteriormente se comprobó que un número no despreciable de estos enfermos también tenían malformaciones en otros órganos. Por haber sido descrito por Peters, ${ }^{2}$ se le dio este nombre a la anomalia del desarrollo de la córnea y cámara anterior. en sus capas ecto y mesodérmicas. Se llama disgenesia primaria si se presenta sólo en el ojo, siendo hereditaria de tipo autosómico recesivo. Si se asocia a malformaciones en otros órganos, se llama disgenesia mesodérmica de la córnea secundaria, siendo causada por cromosomopatías adquiridas como son el síndrome $4 p^{-}$, el $5 q^{-}$, el $18 q$ - o la trisomía $13-15^{3}$ o por embriopatías debidas a tóxicos, avitaminosis, radiaciones o infecciones.

\footnotetext{
* Hospital Luis Calvo Mackenna

**Hosp. Barros Luco-Trudeau.
}

La noxa actuaría produciendo alteración de la córnea, especialmente en su zona central, apareciendo como consecuencia leucoma generalmente bilateral $(80 \%$ de los casos), no creando o haciéndolo de manera defectuosa, el espacio que separa el iris y cristalino del endotelio corneal (defecto de clivaje) y formando sinequias en esa régión ${ }^{4}$ Ello se produciría a partir de la séptima semana de gestación.

Al microscopio electrónico la célula del epitelio anterior está normal, la membrana de Bowman se encuentra ausente en la zona central, siendo reemplazada por fibrillas desorganizadas, el estroma de la parte central y especialmente posterior muestra una desorganización y casi ausencia celular con infiltración de material amorfo, la membrana de Descemet, en la misma región, está muy delgada y reemplazada por un tabique de una substancia similar a la encontrada en el estroma posterior. El endotelio puede o no estar ausente. En la zona periférica de la córnea las capas constitutivas están menos alteradas, pero de aspecto inmaduro. ${ }^{5}$ 


\section{CASOS CLINICOS}

CASO 1. H.S.M., niño de 1 año y 5 meses de sexo masculino No hay antecedentes de consanguinidad entre los ancestros. Padre de 23 años y madre de 20 años, sanos. Es el primer hijo. El padre presenta un coloboma iridiano izquierdo sin otras malformaciones. El embarazo fue controlado como normal, excepto por un cuadro infeccioso de vias respiratorias superiores al $5^{\circ}$ mes y que no requirió tratamiento. No hay antecedentes de drogas ni radiaciones, en el período preconcepcional ni durante el embarazo. El parto fue normal después de 9 meses de gestación, pesando el niño 2.590 grs. En el período neonatal se comprobó un defecto ocular como única patología. El desarrollo psicomotor y pondoestatural posterior fue normal. En la época de su primera consulta a nuestra clínica (17 meses), su talla era de $79 \mathrm{cms}$, el peso de 9.600 grs y la circunferencia de cráneo de $48 \mathrm{cms}$, encontrándose un examen fisico normal, salvo una hernia umbilical pequeña, y en el examen oftalmológico, ojo derecho normal; ojo izquierdo: (Fig. 1) microftalmía con microcórnea de diámetro $9,5 \mathrm{~mm}$, leucoma de aspecto piriforme denso que comprometia todas las rapas. Coloboma iridiano inferior. Cámara anterior estrecha, cristalino normal. El fondo de ojo reveló retina aplicada, no pudiendo apreciarse detalles. Se intervino, desprendiendo adherencias entre iris y cómea, formándole una cámara anterior con suero y dejando para un segundo tiempo un injerto corneal. El examen ocular de la madre fue normal, el del padre comprobó coloboma inferior del iris incompleto a izquierda.

Los dermatoglifos revelaron en el nin̄o: 7 presillas cubitales ( 2 raquetas) y 3 verticilos, observándose en la mano izquierda un trirradio palmar elevado ( $t^{\prime}$ ). Los índices de transversalidad eran de 22 y 24 , ausencia de trirradio $C$ a izquierda. Había un pseudopliegue palmar transverso bilateral. En la madre había 9 presillas cubitales, 2 raquetas y un verticilo, t' que iba a 13 a derecha y t" a 11 , a izquierda. Los índices de transversalidad eran de 26 y 23 , respectivamente. Presentaba presilla cubital hipotenar izquierda y pliegues palmares pseudotransversos a derecha. En el padre revelaron 6 presillas cubitales, 3 verticilos y una presilla radial. Los índices de transversalidad eтan de 17 y 25 , t bilateral a 13, presilla en 7 bilateral. Existía una figura tenar compleja a izquierda.

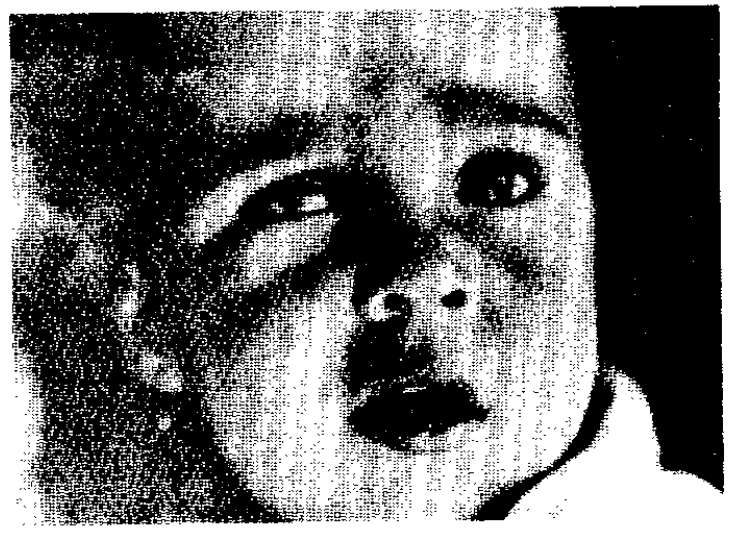

Fig. 1

H.S.M. Se observa microftalmia, microcómea, letucoma del ojo derecho.

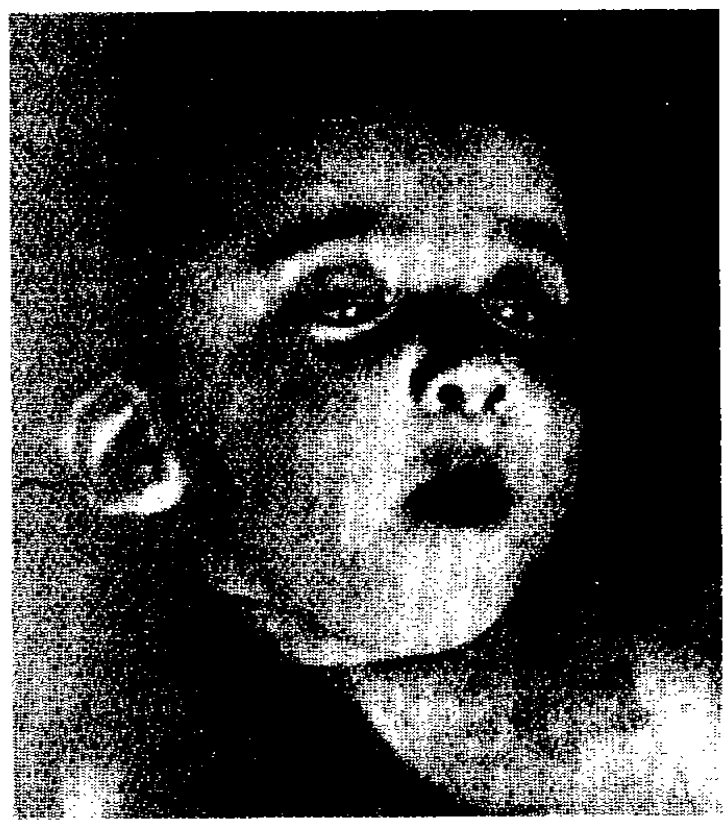

Fig. 2

F.V.M. Leucoma bilateral, pabellones implantados bajos, hélix doblado, anthélix muy marcado.

El cariograma no demostró alteraciones numéricas ni morfológicas en las 24 mitosis analizadas, siendo normal para el sexo masculino.

La prueba de inhibición de la hemaglutinación buscando anticuerpos neutralizantes para rubéola fue negativa tanto en el niño como en la madre.

CASO 2. F.V.M., lactante de 5 meses de edad y sexo masculino. Padre de 32 años, madre de 24 años, y su única hermana, de 2 años 6 meses; todos sanos. No hay antecedentes de consanguinidad, radiaciones, virus ni drogas, excepción hecha de una intoxicación alimenticia de gran magnitud. a los 2 meses de gestación y provocada por mariscos (choritos). Peso de nacimiento, $3.350 \mathrm{grs}$. Buena evolución psicomotora.

Consultó, porque desde el nacimiento tiene alteraciones de sus genitales externos: criptorquídea e hipospadia y lesiones oculares, consistente en leucoma corneal bilateral central (Fig. 2). Diámetro corneal, $9.5 \mathrm{~mm}$; tensión ocular ODI, 20,6 mm. Biomicroscopia: opacidad corneal central densa, especialmente en las capas posteriores, córnea engrosada y edematosa, periferia transparente que permitía ver la cámara anterior estrecha, no se veía la pupila, pareciendo haber sinequias irido-rorneales. En el resto del examen fisico llamó la atención (Fig. 3), pabellones implantados bajos y hélix doblado. Paladar ojival. Un soplo sistólico de carácter funcional y politelía izquierda. Practicado un estudio cardiológico, fue normal. En el examen neurológico se encontró un retraso motor moderado, pero en el resto de las áreas fue normal.

Los dermatoglifos del paciente revelaron: 8 verticilos y 2 presillas cubitales. El trirradio palmar fue normal en ambos lados. Presillas en 7 y 9 bilateral, índice de transversalidad de 26 y 28 , respertivamente. En el padre, 2 verticilos, 8 presillas cubitales, índice de transversalidad 30 
bilateral, t bilateral a 13 , figura hipotenar en mano izquier. da, presilla en 9 bilateral. En la madre, 7 presillas cubitales, 3 verticilos, l' a izquierda y t a derecha. Figuras tenares bilaterales $e$ indice de transversalidad de 25 bilateral. Tiene $p$ en 7 y 9 bilateral

El examen oftalmológico de los padres fue normal, salvo un pequeño leucoma central en ojo izquierdo del padre, de tipo cuerpo extraño.

Se practicaron los siguientes exámenes:

Radiografia de cráneo fue normal: de tórax reveló mediastino superior ensanchado. La pielografia encontró un rinón contra lateral derecho, pero con desembocadura de uréteres normales. La sangre capilar arterializada dio una presión de oxígeno de $70 \mathrm{~mm}$ de mercurio y un porcentaje de saturación de $\mathrm{O}_{2}$ de $94 \%$. Exámenes de orina normales. El raspado bucal fue negativo.

Cariograma del paciente fue normal en 20 mitosis de leucocitos

Anticuerpos para descartar rubécola fueron en el niño negativo $y$ en la madre $1: B 0$.

CASO 3. C.G.C., lactante de 1 mes de edad y sexo masculino. Sin antecedentes de consanguinidad, drogas, virus ni radiaciones. Es el tercer hijo. siendo los otros dos normales. Huloo un aborto provocado anterior. Nació de embarawo normal con un peso de $3.030 \mathrm{grs}$. En el período neonatal presentó crisis de ahogos al alimentarse $y$ ronjuntivitis

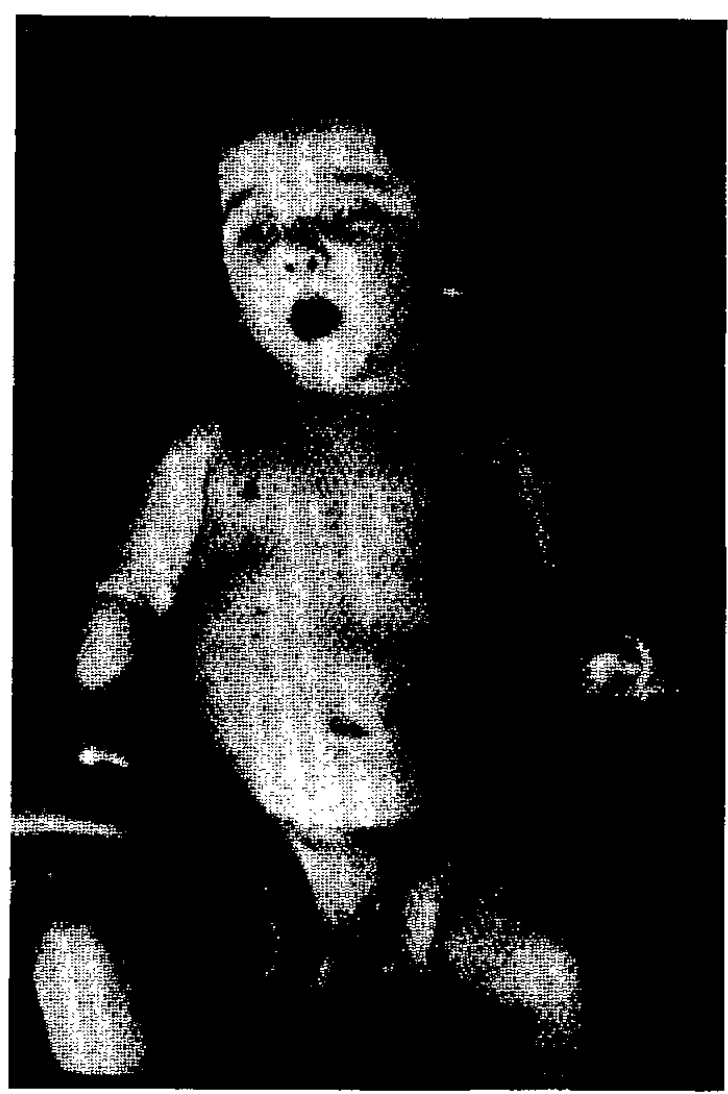

Fig. 3

F.V.M. Se aprecia politelia izquierda, criptorquidea con hipospadia. purulenta. Llamó además la atención una serie de malformaciones por lo que se envió a nuestro centro.

Al examen fisico encontramos un lactante con una talla de $52 \mathrm{cms}$, circunferencia de cráneo $37 \mathrm{cms}$ y tórax $36 \mathrm{cms}$, y un peso de 3.850 grs. Normobraquicéfalo con bregma $5 \times 4 \mathrm{cms}$, hipertelorismo y leucomas corneales bilaterales. Pabellones normales bien implantados, nariz discretamente sentada y lengua bífida central en $1 / 2 \mathrm{~cm}$, succión lenta. Cuello nada especial. Tórax bien conformado. Corazón, soplo sistólico grado $2 / 6$, irradiado al área precordial. Pulmón, estertores húmedos escasos. Abdomen, algo globuloso con vísceras normales. Genitales masculinos normales. Extremidades nada que Ilamara la atención. En cardiología se comprobó: ductus de escaso niujo. Al examen neurológico no se encontró daño evidente. Dermatoglifos: 9 arcos digitales y una presilla cubital. Ausencia de trirradio C bilateral, siendo los otros parámetros irrelevantes, trirradios palmares axiales normales. Habia pseudopliegue palmar transverso bilateral. Un solo pliegue de flexión en $5^{\circ}$ dedo izquierdo. Los del padre revelaron 9 verticilos y una presilla cubital, t bilateral. El indice de transversalidad 30 y 24 . No existen figuras tenares ni hipotenares, pero sí presilla en 7 y 9 . Trirradio accesorio en 7 . Pliegues normales. Los de la madre revelaron 7 presillas cubitales, 2 presillas radiales y 1 verticilo. Pseudopliegue palmar transverso bilateral, $t$ a 13 bilateral. No hay figuras palmares. Indice de transversalidad, 28 bilateral.

En el examen ocular se encontró, en ambos lados, microflalmia, leucoma central vascularizado. cámara anterior muy estrecha, iris claro $\sin$ hipoplasia. Vías lagrimales permeables. Un control al $6^{\circ}$ mes reveló que en el ojo derecho había una evolución favorable por disminución discreta del tamaño del leucoma, pudiendo verse la pupila libre hacia el lado temporal, el ojo izquierdo estaba sin variación.

En su desarrollo psicomotor se encontró retraso leve por hipotonía discreta, buen desarrollo ponderal, pero talla pequeña.

La radiografía de cráneo reveló huesos y volumen normales para su edad. Examen de mucopolisacáridos: negativo. Cariograma: las 20 mitosił analizadas fueron normales y correspondieron al sexo masculino.

La búsqueda de anticuerpos para rubéola (IgG) reveló en el niño un título de 1:40 y en la madre un título de $1: 10$.

\section{COMENTARIO}

Hemos presentado tres casos de disgenesia mesodérmica de la córnea; el primero compromete sólo a un ojo y no tiene otras malformaciones agregadas, en cambio los dos últimos tienen anomalías en otros órganos. Esto nos hace presumir que el caso unilateral tendría un posible origen genético, hereditario, corroborado por el hallazgo de coloboma en el padre, ya que se ha descrito alteraciones oculares mínimas en los heterocigotos que harían sospechar el estado de portador. ${ }^{6}$ También lo hace altamente sospechoso una alteración de dermatoglifos en los progenitores, que reme- 
dan a los de nuestro paciente. Los dos últimos, en cambio, parecen ser de origen adquirido, pero la noxa causante no se pudo precisar. Encontramos, sí, sugestivo el antecedente de intoxicación al segundo mes de embarazo, en una de las madres. Los tres casos se presentan en el sexo masculino, lo que sólo podemos atribuirlo al azar, ya que no hay predilección por sexo, ni en la herencia recesiva ni en la embriopatía. ${ }^{6}$

Los dermatoglifos nos indican que el defefecto del desarrollo se produce en una etapa precoz, alterando tanto los mamelones de los rudimentos palmares, digitales y de otros órganos. Al encontrar una anomalía de Peters deberá buscarse malformaciones ocultas. ${ }^{2}$ Los órganos más afectados pueden ser: el sistema nervioso central, dando quistes subcorticales de la substancia blanca, hidrocefalia, espina bífida oculta o sordera; en el sistema cardiovascular se presentan defectos septales, estenosis de la pulmonar o ductus; en el sistema renal, hipospadia, criptorquídea, estenosis ureterales, hidrouréter, hidronefrosis, duplicaciones ureterales, etc.; en el sistema óseo puede haber displasia craneal, hipertelorismo, micrognasia, microcefalia, palatosquisis, pie bot o polidactilia; en el sistema digestivo, atresia intestinal $y$, en fin, otras malformaciones como hernia del ombligo, Pterigium colli, anomalías de pabellones auriculares, ${ }^{2}$ etc.

Debemos decir que la mejoría relativa observada en el leucoma del último de nuestros pacientes es explicable por disminución del edema corneal, lo que no hace variar el pronóstico general.

De lo dicho anteriormente se desprende que el diagnóstico precoz lleva a un tratamiento adecuado y oportuno del enfermo. ${ }^{7}$ El pronóstico en cuanto a vida, desarrollo intelectual y repetición en otros parientes del enfermo con anoma- lía de Peters, variará de acuerdo a su etiología y al compromiso de órganos vitales. Creemos que es fundamental el estudio de los progenitores para dar un consejo genético adecuado a cada caso y evitar su repetición depurando las noxas conocidas. Los de origen adquirido podrán procrear hijos normales, de acuerdo a las limitaciones que ellos presenten.

\section{RESUMEN}

Se presentan tres casos de anomalía de Peters, el primero de origen hereditario, sospechado por alteraciones oculares del padre y estudio de dermatoglifos y los otros dos, probablemente adquiridos, sin encontrarse la causa precisa de su producción.

Se analiza la etiología, el diagnóstico, la evolución y el tratamiento bajo el punto de vista pediátrico. Se comenta su posible prevención.

\section{SUMMARY}

Three cases with Peters' anomaly are presented. One is presumed to be hereditary in origen, mainly because of the father's ocular pathology and dermatoglyphic studies. Two others are probably adquired during pregnancy, but not known noxe was found.

Discussion on the ethiology, diagnosis, follow up and treatment, under the pediatric point of view, and it possible prevention is commented.

\section{REFERENCIAS}

1 Ravault, M.P. Syndroms in ophthalmology. Guide Dictionary, 1970.

2 Alkemade, P.P.H. Dysgenesis mesodermalis of the iris and the cornea. Thomas. Springfield, 1969.

3 Francois, J., $\boldsymbol{R}$. Berger, et $\boldsymbol{H}$. Sareux. Les aberrations chromosomiques en ophtalmologie, 1972.

4 Reese, A.B. and R.M. Ellsuorth. Arch. of Ophthal., 75: 307,1966

- Nakanishi, I. and S.J. Brown. Am. J. Ophthal., 72:801, 1971

- Carenini, B. Boll. oculist., 45:593, 1966.

7 Brown, S.I. Am. J. Ophthal., 79:942, 1970.

Trabajo entregado para su publicación en 1975. 